\title{
Transitory immunologic response after implantation of the DeBakey VAD continuous-axial-flow pump
}
H. J. Ankersmit, MDa
G. Wieselthaler, MD
B. Moser, MDa
S. Gerlitz, RN ${ }^{b}$
G. Roth, MD
G. Boltz-Nitulescu, PhDc
E. Wolner, MDa

From the Departments of Surgery, Immunodermatology, ${ }^{\mathrm{b}}$ and Experimental Pathology, ${ }^{c}$ General Hospital Vienna University, Wien, Austria.

This paper was supported by the Boltzmann Institut für Herzchirurgische Forschung and grant 8920, Austrian National Bank.

Received for publication May 31, 2001; revisions requested July 9, 2001; revisions received July 16, 2001; accepted for publication Aug 15, 2001.

Address for reprints: Hendrik Jan Ankersmit, MD, Department of Surgery, General Hospital Vienna University, Währinger Gürtel 18-20, 1090 Wien, Austria (E-mail: hjankersmit@hotmail.com).

H. J. Ankersmit and G. Wieselthaler contributed equally to this article.

J Thorac Cardiovasc Surg 2002;123:557-61

Copyright (c) 2002 by The American Association for Thoracic Surgery

$0022-5223 / 2002 \$ 35.00+0 \quad \mathbf{1 2 / 1 / 1 2 0 0 1 1}$

doi:10.1067/mtc.2002.120011
Background: The development of local and systemic infection is a significant risk factor associated with implantation of a ventricular assist device. The immunologic consequence of continuous-flow rotary blood pumps is not known.

Methods: Six male adult patients (mean age $47 \pm 10.3$ ) with end-stage left heart failure received a DeBakey VAD axial-flow pump for use as a bridge to transplantation. (Four patients underwent transplantation after a mean $115 \pm 14$ days; 2 patients are still waiting for the allograft.)

Results: We prospectively monitored T-cell populations and apoptosis-specific aberrant T-cell activation via CD95 triggering and annexin V binding to lymphocytes, identifying $\mathrm{T}$ cells undergoing early phases of apoptosis, within the first 10 weeks. Moreover, soluble death-inducing receptors soluble CD95 and soluble tumor necrosis factor-R1 were evaluated by enzyme-linked immunosorbent assay.

Conclusion: Patients bridged to transplantation by a nonpulsatile ventricular assist device demonstrated an initial pronounced apoptosis-specific immune alteration by increased annexin $\mathrm{V}$ binding to $\mathrm{CD} 3 \mathrm{~T}$ cells and death-inducing receptors soluble CD95/tumor necrosis factor-R1 (all $P<.001$ ). All parameters normalized after 7 weeks to baseline. No blood-borne sepsis was detected, as defined by blood culture, within the first 10 weeks of the cohort study. These results indicate a biphasic immunologic response in patients with end-stage heart failure treated with nonpulsatile ventricular assist devices.

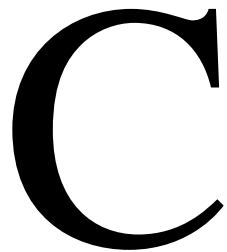

ongestive heart failure is a major public health issue, and the pulsatile ventricular assist device (VAD) has been proven to be beneficial in bridging patients to allograft transplantation with encouraging medium-term results. ${ }^{1,2}$ A prospective, randomized, multicenter trial of the permanent implantation of a left ventricular assist device (LVAD) for patients with end-stage heart failure is under way. ${ }^{3}$ The clinical success of LVAD implantation has been accompanied by complications such as thromboembolic events ranging from $5 \%$ to $30 \%$ of $^{\text {cases }}{ }^{4-6}$ and an increased rate of systemic infections, which has been reported in $25 \%$ to $40 \%$ of VAD recipients irrespective of device type used. ${ }^{7,8}$ Although some of these infections were attributed to drive line, pocket, and perioperative complications, the frequent identification of fungal and bacterial infections has led to investigations in the genesis of immune defect caused by VAD-immune system interaction. These observations have led to the conclusion that LVAD implantation is accompanied by progressive defects in cellular immunity and was associated with an induction of an aberrant T-cell activation involving the CD95 (Fas) pathway and activation-induced cell death of CD4 T cells. ${ }^{9}$ 
TABLE 1. Demographic and clinical features of patients

\begin{tabular}{|c|c|c|c|c|c|c|}
\hline & Case 1 & Case 2 & Case 3 & Case 4 & Case 5 & Case 6 \\
\hline Sex & Male & Male & Male & Male & Male & Male \\
\hline Age & 65 & 46 & 45 & 37 & 38 & 52 \\
\hline Diagnosis & Dilatative CMP, s/p MI & Ischemic CMP & Ischemic CMP & $\mathrm{s} / \mathrm{p}$ myocarditis & Idiopathic CMP & Ischemic CMP \\
\hline Indication & $\begin{array}{l}\text { Terminal cardiac } \\
\text { insuf. }\end{array}$ & $\begin{array}{l}\text { s/p Ml; terminal } \\
\text { cardiac insuf. }\end{array}$ & $\begin{array}{l}\text { Terminal cardiac } \\
\text { insuf. }\end{array}$ & DCM dec. & DCM dec. & $\begin{array}{l}\text { Terminal cardiac } \\
\text { insuf. }\end{array}$ \\
\hline Duration (d) & 120 & 96 & Ongoing & Ongoing & 116 & 130 \\
\hline Weaning HTX & Yes & Yes & No & No & Yes & Yes \\
\hline Survival & Yes & Yes & Yes & Yes & Yes & Yes \\
\hline Blood-borne infection & No & No & No & No & No & No \\
\hline
\end{tabular}

$C M P$, Cardiomyopathy; $s / p$, status post; $M I$, myocardial infarction; insuf., insufficiency; dec., $\bullet{ }^{\circ} ; H T X$, heart transplantation.

Axial-flow impeller pumps, with their potential for small size, low noise, and absence of a compliance chamber, have been developed for clinical use during the past 10 years. Of 4 potential candidates (Jarvik 2000 [CardioWest Technologies, Inc, Tucson, Ariz], DeBakey VAD [MicroMed Technology, Inc, Houston, Tex], Nimbus/Pittsburgh axial-flow blood pump [Nimbus, Inc, Rancho Cordova, Calif], and Sun Medical/HIJ, Waseda/Pittsburgh intraventricular axial-flow blood pump), ${ }^{10-13}$ the DeBakey VAD was the first clinically used with successful consecutive transplantation. ${ }^{14}$ To assess the long-term rather than perioperative immunologic impact, we aimed to analyze the recipient's immune status, presence of death-inducing receptors, and apoptosis of the recipient's $\mathrm{T}$ cells before as well as during the first 10 weeks in a sequential manner. Blood-borne sepsis was defined by positive blood culture.

\section{Materials and Methods \\ DeBakey VAD}

The electromagnetically actuated DeBakey VAD is a miniaturized pro-peritoneal implantable titanium axial-flow blood pump. A titanium inflow cannula connects the pump to the apex of the left ventricle, and a Vascutek Gelweave vascular graft (Vascutek, Renfrewshire, Scotland) as an outflow conduit connects the pump to the ascending aorta. An ultrasonic flow probe is placed around the outflow conduit. Together with the probe's wiring, the pump motor cable exits the skin above the right iliac crest and attaches to the VAD's external controller system. The pump is designed to achieve $5 \mathrm{~L} / \mathrm{min}$ against $100 \mathrm{~mm} \mathrm{Hg}$ pressure, with a rotor speed of $10,000 \mathrm{rpm}$ and power input of less than $10 \mathrm{~W}$. The measured pump flow is displayed either on the external VAD controller or when connected on the clinical data acquisition system (CDAS) together with pump speed, power consumption, and current signals from the pump. Adjustments to the pump speed can be performed only when it is connected to the CDAS. For optimal mobilization of the patient and freedom to move, power can be delivered by two $12-\mathrm{V}$ direct-current batteries for several hours.

\section{Patients}

Six male patients with end-stage left heart failure received a DeBakey VAD as an LVAD for bridging to transplantation. All patients were listed for cardiac transplantation and showed signs of acute hemodynamic deterioration and end-organ dysfunction at the time of implantation (Table 1). All patients were placed on broad antibiotic prophylactic therapeutic regimens in the perioperative time. The study protocol was in compliance with the rules of the Ethical Review Board of Vienna University Hospital.

\section{Immune Phenotype of Circulating T Cells and Expression of CD95/Fas and CD45RO on Peripheral T Cells}

Immunologic investigations were done in 6 recipients of DeBakey nonpulsatile VADs in a sequential manner. Cell counts from patients were achieved by FACS (fluorescence-activated cell sorter) counter analysis. We used fluorochrome-labeled monoclonal antibodies to CD4, CD8, CD3, CD45RO (T-cell memory marker), and CD95 (Apo-1) in 2-color or 3-color immunofluorescence analyses, as previously described by Robins. ${ }^{15}$ Log fluorescence was measured by a FACScan 500 flow cytometer (Becton Dickinson Systems, San Jose, Calif).

\section{Soluble Death-inducing Receptors Tumor Necrosis Factor-R1 and CD95}

Serum samples were obtained from study populations and kept frozen. Circulating serum levels of soluble CD95 (sCD95) and soluble receptor of tumor necrosis factor (sTNF-R1) were measured in a commercial enzyme-linked immunosorbent assay (ELISA) by using polyclonal antibodies against human CD95 and TNF-R1 (Cytoscreen, Biosource International, Inc, Camerillo, Calif [sCD95], and R\&D Systems Inc, Minneapolis, Minn [sTNFR1]). The sensitivity of the ELISA is $20 \mathrm{pg} / \mathrm{mL}$ and $3 \mathrm{pg} / \mathrm{mL}$, respectively. The amount of protein in each serum sample was calculated according to a standard curve of optical density values constructed for a known level of sCD95/sTNF-R1 protein.

\section{T-cell Apoptosis In Vivo}

Flow cytometry peripheral blood mononuclear cells (PBMCs) were analyzed with a flow cytometric apoptosis detection kit (Becton Dickinson Systems, Franklin Lakes, NJ). PBMCs $3 \times 10^{5}$ were stained with phycoerythrin-conjugated monoclonal antibodies to CD3 and then co-stained with $10 \mu \mathrm{L}$ fluorescein-isothiocyanateconjugated annexin V (R\&D Systems, Minneapolis, Minn) to detect phosphatidylserine expression on cells during early apo- 
ptotic phases. Dead cells were excluded with 7-amino actinomycin D. The samples were analyzed by a FACStar 500 cytometer.

\section{Statistical Analyses}

The percentage of lymphocytes was deemed significantly altered when values differed mean $\pm 2 \mathrm{SD}$. Continuous variables such as protein content were analyzed by the Student $t$ test.

\section{Results}

Immunophenotypic Analysis of T Cells

The percentage of circulating $\mathrm{T}$ lymphocytes and CD4/CD8 subsets did not alter significantly in the course of the implantation period in the study population (Figure 1, A).

\section{Expression of CD95/Fas and CD45RO on Peripheral T Cells}

Because specific and nonspecific triggering of $\mathrm{T}$ lymphocytes is inducing apoptosis in vitro, we investigated whether expression of CD95 (Apo-1) and levels of the T-cell memory marker CD45RO were upregulated. The results are depicted in Figure 1, B. The expression of CD95, a molecule associated with a pathway of cellular apoptosis, was increased to a similar degree in $\mathrm{CD} 3+\mathrm{T}$ cells before and after implantation. Similar values were also verified by CD45RO, a marker indicating the T-cell memory population $(P<\mathrm{NS})$.

\section{Soluble CD95 and TNF-R1}

Because translocation of phosphatidylserine as an early component of T-cell apoptosis occurs after ligation of CD95 and TNF engagement, we investigated whether related soluble shedding forms of CD95 and TNF-R $1^{16}$ were present in the serum. As shown in Figure 1, $C$, the mean serum levels of sCD95 rose sharply after implantation of nonpulsatile VAD and decreased after 6 weeks to baseline values before implantation (before implantation, 3 weeks, 6 weeks [sCD95 $1.32 \pm$ $0.21,7.6 \pm 4.2,0.9 \pm 0.7 \mathrm{pg} / \mathrm{mL}$; sTNF-R1 $1.5 \pm 0.23,10 \pm$ $6.9,2.1 \pm 0.8 \mathrm{ng} / \mathrm{mL}], P<.01$ between all values).

\section{Spontaneous T-cell Apoptosis In Vivo}

In further experiments we addressed whether the elevated state of T-cell activation is associated with an increased percentage of peripheral $\mathrm{T}$ cells undergoing apoptosis. The results depicted in Figure 1, $B$, show that, before implantation, CD3+ $\mathrm{T}$ cells had increased binding to annexin $\mathrm{V}$ $(18 \% \pm 8.5 \%)$, increased until the fourth week $(41.4 \% \pm$ $9.3 \%)$, and leveled down by week $7(10.8 \% \pm 3 \%)$. In vivo dead cell exclusion was performed in all samples. All samples contained less than $0.5 \% 7$-amino actinomycin D positive cells.

\section{Discussion}

In this report we have shown that patients after implantation of nonpulsatile VAD present a biphasic immunologic reac-
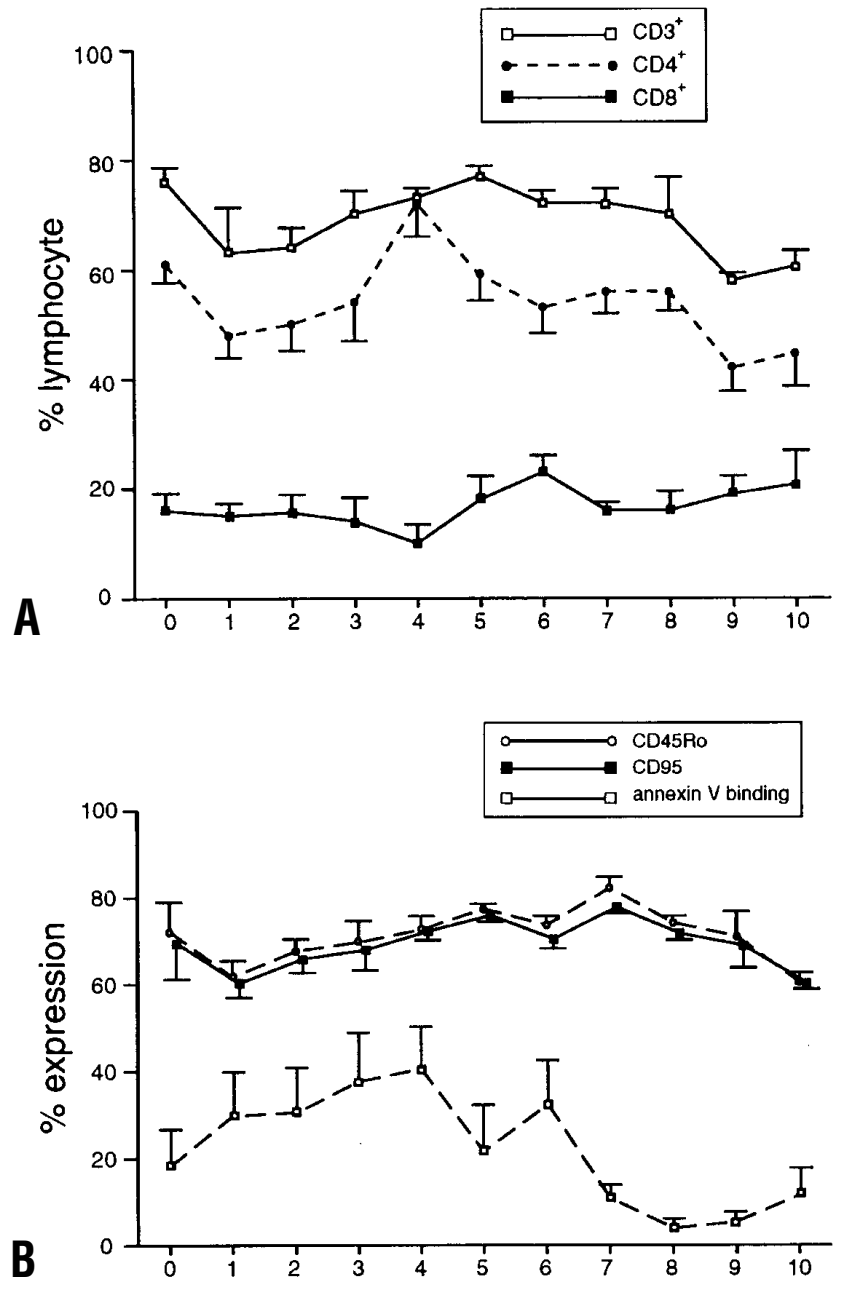

C

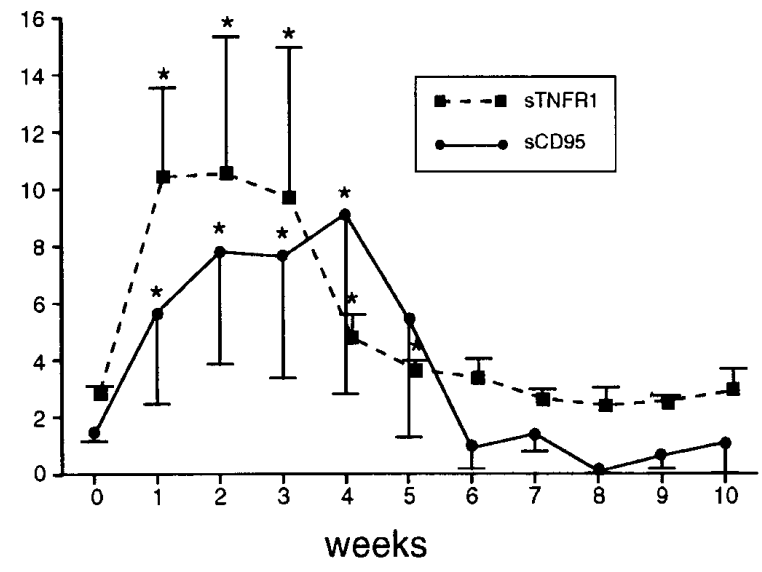

Figure 1. Changes in cell phenotype, cell activation, and antigen shading during 10 weeks after implantation of the DeBakey pump. Freshly isolated PBMC from 6 patients were stained with monoclonal antibody anti-CD3, CD4, CD8 (panel A) or with anti-CD3 and CD45RO, and/or annexin V (panel B) and subjected to FACS analysis. Soluble CD95 $(\mathrm{pg} / \mathrm{mL})$ and sTNFR1 $(\mathrm{ng} / \mathrm{mL})$ were measured in sera by ELISA, and the results are depicted in panel $C$. Data are presented as mean \pm SE. Statistical significance: ${ }^{*} P<.01$. 
tivity as seen with the immediate rise in soluble deathinducing receptors TNF-R1 and CD95 with no alteration in the percentage of $\mathrm{T}$ cells and CD4/8 ratio in sequential fashion. Moreover, a significant decrease of annexin $\mathrm{V}$ binding, indicating $\mathrm{T}$ cells undergoing early phases of apoptosis, was verified after a mean implantation of 7 weeks. These results support that initially there is a similar immunoaction present as shown in a cross-sectional fashion in recipients of TCI (Thoratec Corporation (Pleasanton, Calif) and Novacor (Baxter Healthcare Corp, Novacor Div, Oakland, Calif) VADs. ${ }^{9}$ Previous hypotheses were attributing chronic interleukin 6 activation with T-cell suppression and a shift from a Th1 to Th $2^{17}$ with consecutive induction of B-cell hyperreactivity as possible explanations for decreased T-cell immunity. It was furthermore reported that VAD implantation was also associated with formation of HLA class I and II antibodies. ${ }^{18}$ Recent observations have demonstrated that patients with pulsatile VADs demonstrate an aberrant T-cell activation with CD4 T cells being selectively susceptible toward activation-induced cell death and, moreover, demonstrated inversed CD4/8 ratio and increased Th2 cytokine IL10 (interleukin 10). ${ }^{19}$ In addition to these observations, $\mathrm{we}^{20}$ have demonstrated recently that patients who are undergoing hemodialysis demonstrate immunoactivation similar to that of patients who have received a pulsatile LVAD. In both entities prolonged blood/immune system polymer interaction is prevalent. As patients with an LVAD are not receiving any immunosuppression, we previously deduced that long-term exposure to an antigen, for example, the LVAD surface (polyurethane) or other polymers such as silicone, polytetrafluoroethylene, or Dacron, is able to trigger a state of susceptibility toward programmed cell death $^{21,22}$ and thus is able to induce a defect in in vitro experiments. We were able to demonstrate that commonly used polymers are able to act as superantigens, hence are inducing the upregulation of nuclear factor of activated $\mathrm{T}$ cells and selective Fas ligand enhancement, as detected by immunoblot analysis. This was further verified by induction of caspase 8 and 3 upregulation in naive PBMCs exposed to biomaterial; this indicates that a proapoptotic pathway is initiated by a chemical that is leaching of the biopolymer. Moreover, the increased likelihood of PBMCs of patients requiring dialysis to undergo activated induced cell death is further supported by recent publications that demonstrated the presence of plastic softeners in such patients in vivo and their potential immunosuppressive capacity in vitro. ${ }^{23,24}$ With this in mind, one might speculate that a similar mechanism might be partially responsible for immunoactivation in patients treated with pulsatile VADs, devices that are constructed with large polyurethane surfaces. If our interpretation of the data is correct, the small size and steel containment of the mini-axial flow pump might have increased biocompatibility because of increased material inertness and possibly more physiologic flow characteristics. This, however, remains to be determined and warrants separate in vivo and vitro studies. Since mechanical support is under investigation as a definitive treatment for heart failure, clinical evaluations have been initiated. Moskowitz and associates $^{25}$ identified that infection is the main cause of death in patients receiving pulsatile VADs, hence demonstrating no survival benefit of the VAD group in the PreREMATCH study versus conventional medical treatment. Since nonpulsatile VADs are becoming standard therapy, ${ }^{26}$ our lessons learned from our clinical experience are the following: (1) Nonpulsatile VADs induce a biphasic immunologic response, as seen by a steep rise of soluble death-inducing receptors CD95 and sTNF-R1 with increased annexin V binding to CD3 leukocytes; (2) percentage of lymphocytes and CD4/8 ratio do not alter in the study cohort; (3) a significant decrease of mean annexin $\mathrm{V}$ binding to $\mathrm{T}$ lymphocytes occurs after 7 weeks in patients with the DeBakey VAD; and (4) no blood-borne infections were observed in the first 10 weeks in the patient cohort. In conclusion our immunologic results indicate that patients demonstrate a biphasic apoptosis-specific activation pathway that is prevalent initially and decreases within 7 weeks. We learned that prophylactic antibiotic/mycotic drug therapy is able to rule out systemic infections within the first weeks of VAD installation. These results suggest that this new technology has less immunologic consequence and ideally will invigorate trials including nonpulsatile VADs as definitive therapy.

We thank Jan Ankersmit, MD for designing the study, G. Wieselthaler for clinical management, B. Moser, MD, G. Roth, $\mathrm{MD}$, and S. Gerlitz, RN, for the laboratory work, and E. Wolner, $\mathrm{MD}$, and $\mathrm{G}$. Boltz-Nitulescu, $\mathrm{PhD}$, for infrastructure support.

\section{References}

1. Frazier OH, Rose EA, Macmanus Q, Burton NA, Lefrak EA, Poirier VL, et al. Multicenter clinical evaluation of the HeartMate 1000 IP left ventricular assist device. Ann Thorac Surg. 1992;53:1080-90.

2. McCarthy PM, Portner PM, Tobler HG, Starnes VA, Ramasamy N, Oyer PE. Clinical experience with the Novacor ventricular assist system: bridge to transplantation and the transition to permanent application. J Thorac Cardiovasc Surg. 1991;102:578-87.

3. Rose EA, Moskowitz AJ, Paker M, Sollano JA, Williams DL, Tierney $\mathrm{AR}$, et al. The REMATCH trial: rationale, design, and end points. Randomized Evaluation of Mechanical Assistance for the Treatment of Congestive Heart Failure. Ann Thorac Surg. 1999;67:723-30.

4. Didisheim P. Current concepts of thrombosis and infection in artificial organs. ASAIO J. 1994;40:230-37.

5. Wagner WR, Johnson PC, Kormos RL, Griffith BP. Evaluation of bioprosthetic valve-associated thrombus in ventricular assist device patients. Circulation. 1993;88:2023-29.

6. Rose EA, Levin HR, Oz MC, Frazier OH, Macmanus Q, Burton NA, et al. Artificial circulatory support with textured interior surface: a counterintuitive approach to minimizing thromboembolism. Circulation. 1994;90(Suppl):II-87-91.

7. McCarthy PM, Schmitt SK, Vargo RL, Gordon S, Keys TF, Hobbs RE. Implantable LVAD infections: implications for permanent use of the device. Ann Thorac Surg. 1996;61:359-65. 
8. Fischer SA, Trenholme GM, Copstanzo MR, Piccione W. Infectious complications in left ventricular assist device recipients. Clin Infect Dis. 1997;24:182-3.

9. Ankersmit HJ, Tugulea S, Spanier S, Weinberg AD, Artrip JH, Burke EM, et al. Activation-induced T-cell death and immune dysfunction after implantation of left-ventricular assist device. Lancet. 1999;354: 550-5.

10. Macris MP, Parnis SM, Frazier OH, Fuqua JM Jr, Jarvik RK. Development of an implantable ventricular assist system. Ann Thorac Surg. 1997;63:367-70.

11. DeBakey ME, Benkowski R. The DeBakey/NASA axial flow ventricular assist device. In: Akutsu T, Koyanagi H, editors. Heart replacement and artificial heart 6. Tokyo, Japan: Springer Verlag; 1998. p. 407-13.

12. Butler K, Thomas D, Antaki J, Borovetz H, Griffith B, Kameneva M, et al. Development of the Nimbus/Pittsburgh axial flow left ventricular assist system. Artif Organs. 1997;21:602-10.

13. Yamazaki K, Kormos R, Mori T. An intraventricular axial flow blood pump integrated with bearing purge system. ASAIO J. 1995;41:327-32.

14. Wieselthaler GM, Schima H, Hiesmayer M, Pacher R, Laufer G, Noon GP, et al. First clinical experience with the DeBakey VAD continuous-axial-flow pump for bridge to transplantation. Circulation. 2000;101:356-9.

15. Robins JP. Current protocols in cytometry. Vols 1 and 2. New York: John Wiley; p. 1997.

16. Pimentel-Muitos FX, Seed B. Regulated commitment of TNF receptor signaling: a molecular switch for death or activation. Immunity. 1999;11:783-93.

17. Deng MC, Erren M, Tjan TDT, Tamminga N, Werntze B, Zimmermann $\mathrm{P}$, et al. Left ventricular assist system support is associated with persistent inflammation and temporary immunosuppression. Thorac Cardiovasc Surg. 1999;47:326-31.

18. Itescu S, Tung T, Burke EM, Weinberg A, Moazami N, Artrip JH, et al. Preformed IgG antibodies against major histocompatibility complex class II antigens are major risk factors for high-grade cellular rejection in recipients of heart transplantation. Circulation. 1998; 98:786-93.

19. Ankersmit J, Schuster M, Kocher AA, Edwards NM, Oz MC, Itescu S. T-cell activation in left ventricular assist device (LVAD-) recipients occurs via a CD-95 dependent pathway and results in loss of Th-1 cells and high levels of circulating IL-10. Surg Forum Am Coll Surg. 1999;50:392-3.

20. Ankersmit HJ, Deicher R, Moser B, Teufel I, Roth G, Gerlitz S, et al. Impaired T- cell proliferation, increased soluble death-inducing receptors and activation-induced T-cell death in patients undergoing haemodialysis. Clin Exp Immunol. 2001;125:142-8.

21. Ankersmit J, Schuster M, Hoffmann M, Kocher A, Wolner E, Rose E, et al. Polymeric biomaterials induce T-cell apoptosis and defects in cellular immunity via increased cellular levels of NFAT and CD95 ligand expression and CD95L [abstract]. J Heart Lung Transplant. 2000;78.

22. Ankersmit J, Hoffmann M, Olson K, Kocher A, Oz MC, Edwards $\mathrm{NM}$, et al. Polymeric biomaterials act as superantigens, causing T-cell apoptosis via induction of CD95 ligand expression and defects in cellular immunity [abstract]. Circulation.1999;100(Suppl):I-802.

23. Fischer FP, Machleidt C, Rettenmeier AW, Kuhlmann U, Mettang T. Plasticizers and inhibition of leukocyte function in vitro. Perit Dial Int. 1998;18:620-5.

24. Dine T, Luyckx M, Gressier B, Brunet C, Souhait J, Nogarede S, et al. A pharmacokinetic interpretation of increasing concentrations of DEHP in haemodialysed patients. Med Eng Phys. 2000;22:157-65.

25. Moskowitz AJ, Shapiro PA, Sollano JA, Heitjan DF, Meier P, Stevenson LW, et al. Left ventricular assist device as long-term therapy for severe heart failure: pilot study results demonstrate feasibility of randomized trial. Circulation. 1999;100(Suppl):I-514.

26. Wieselthaler GM, Schima H, Lassnig AM, Dworschak M, Pacer R, Grimm M, et al. Lessons learned from the first clinical implants of the DeBakey ventricular assist device axial pump: a single center report. Ann Thorac Surg. 2001;71:S139-43. 